\title{
PENGARUH PERSEPSI GAYA KEPEMIMPINAN TRANSFORMASIONAL DAN KEPUASAN KERJA TERHADAP ORGANIZATION CITIZENSHIP BEHAVIOR: PERAN KOMITMEN ORGANISASIONAL SEBAGAI PEMEDIASI (SURVEY PADA KARYAWAN BPR DI WILAYAH SURAKARTA)
}

\author{
Rohwiyati ${ }^{1)}$ \\ Praptiestrini $^{2)}$
}

Fakultas Ekonomi Universitas Surakarta

e-mail: ${ }^{1)}$ rohwiyatiunsa1978@gmail.com ; ${ }^{2)}$ prapti.unsa@gmail.com

\begin{abstract}
This study aims to analyze (1) effect perceptions of transformational leadership and job satisfaction on organizational commitment, (2) effect perceptions of transformational leadership, job satisfaction, and organizational commitment on organizational citizenship behavior, (3) effect perceptions of transformational leadership and job satisfaction on organizational citizenship behavior through organizational commitment. Samples on this research of 103 BPR employees in the Surakarta region. Data analysis using path analysis. Conclusions (1) transformational leadership perceptions and job satisfaction have a significant effect on organizational commitment, (2) transformational leadership perceptions, job satisfaction, and organizational commitment have significant effect on organizational citizenship behavior, (3) organizational commitment mediate the effect perceptions of transformational leadership and job satisfaction on organizational citizenship behavior.
\end{abstract}

Keywords: perceptions of transformational leadership, job satisfaction, organizational commitment, organizational citizenship behavior

\section{PENDAHULUAN}

Studi mengenai perilaku organisasi sampai sekarang memainkan peranan penting dalam mencapai perkembangan organisasi dan keberhasilan kerja. Perilaku organisasi menjadi semakin penting dalam ekonomi global ketika orang-orang dalam organisasi dengan berbagai perbedaan, latar belakang, dan nilai budaya harus bekerja sama secara efektif dan efisien.

Semua organisasi ingin sukses, bahkan di lingkungan saat ini yang sangat kompetitif, oleh karena itu perusahaan berusaha untuk mempertahankan karyawan terbaik, mengakui peran dan pengaruh penting mereka pada keefektifan organisasi. Untuk mengatasi tantangan ini, perusahaan harus menciptakan hubungan yang kuat dan positif dengan karyawannya dan mengarahkan mereka menuju pemenuhan tugas (Debro, 2013). Kinerja karyawan turut mendukung pencapaian tujuan dan kesuksesan organisasi, apabila kinerja karyawan baik umumnya kinerja organisasi 
EKONOMI BISNIS DAN KEWIRAUSAHAAN

Vol. VIII, No. 1, Januari 2019

juga baik. Kinerja individu pada dasarnya tidak hanya diwujudkan dalam bentuk kinerja tugas (job performance) secara formal tetapi juga dapat diukur dari perilaku ekstra peran atau sering disebut dengan organizational citizenship behavior. Kedua bentuk kinerja tersebut kemudian populer dengan istilah in-role dan extra-role performance. Dalam konteks perilaku keorganisasian, perilaku ekstra peran (OCB) amat penting dimiliki karena turut memberikan kontribusi positif terhadap kualitas kehidupan kerja dan kinerja organisasi. Melalui organizational citizenship behavior, karyawan diharapkan memahami keberadaan organisasinya dengan segala keterbatasan dan dengan suka rela memiliki komitmen terhadap keefektifan fungsifungsi organisasi. Pada saat organisasi dihadapkan pada berbagai situasi yang kurang kondusif dan kualitas kehidupan kerja menurun maka perilaku perilaku ekstra peran (OCB) perlu didukung. Sebagai warga organisasi yang baik akan tetap berperilaku positif dan bersedia dengan suka rela untuk menunjukkan berbagai perilaku kerja di luar peran yang seharusnya dijalankan (in-role).

Menurut Steers, Porter, Bigley (1996) organizational citizenship behavior (OCB) adalah sikap membantu yang ditunjukkan oleh anggota organisasi, yang sifatnya konstruktif, dihargai oleh perusahaan tapi tidak secara langsung berhubungan dengan produktivitas individu. Contoh perilaku yang termasuk kelompok OCB adalah suka membantu rekan kerja, sukarela melakukan kegiatan ekstra di tempat kerja, menghindari konflik dengan rekan kerja, melindungi properti organisasi, menghargai peraturan yang berlaku di organisasi, toleransi pada situasi yang kurang ideal/menyenangkan di tempat kerja, memberi saran-saran yang membangun di tempat kerja, serta tidak membuang-buang waktu di tempat kerja. Menurut Organ dalam LePine, Erez, dan Johnson (2002:53) bentuk perilaku ekstra peran (OCB) dapat diimplementasikan dalam bentuk perilaku yaitu (1) Altruism yaitu perilaku membantu dengan segera terhadap orang lain; (2) Conscientiousness yaitu sikap berhati-hati/mendengarkan kata hati. (3) Sportmanship yaitu sikap sportif seperti toleransi terhadap ketidaknyamanan dalam bekerja yang tidak dapat dihindari tanpa adanya komplain. (4) Courtesy yaitu kesopanan seperti memberitahu yang lain dalam mencegah kejadian dalam kerja yang menimbulkan suatu masalah. (5) Civic virtue yaitu berpartisipasi dan memperhatikan kelangsungan hidup perusahaan.

Untuk menjawab permasalahan dan tantangan bisnis masa depan, organisasi harus pandai mengelola perubahan serta menetapkan strategi yang tepat. Salah satu strategi yang ditempuh misalnya melalui kepemimpinan yang transformasional. Kepemimpinan transformasional sampai saat ini marak dibicarakan dan dipandang sebagai stategi kepemimpinan yang mulai banyak diterapkan organisasi. Konsep awal tentang kepemimpinan trasformasional telah diformulasikan oleh Burns (1978). Teori kepemimpinan Transformasional dibangun atas gagasan-gagasan awal yaitu tingkat sejauh mana seorang pemimpin dapat disebut sebagai pemimpin transformasional. Figur seorang pemimpin transformasional dapat diukur dalam hubungannya dengan efek pemimpin tersebut terhadap para bawahan yaitu adanya kepercayaan, kekaguman, kesetiaan, dan rasa hormat terhadap pemimpin tersebut 
Vol. VIII, No. 1, Januari 2019

dan mereka termotivasi untuk melakukan hal-hal yang lebih dari pada yang awalnya diharapkan pemimpin.

Pemimpin transformasional mempengaruhi bawahan dengan memotivasi dan menginspirasi mereka untuk mencapai tujuan organisasi. Pemimpin transformasional juga mencoba untuk membantu para bawahan untuk mencapai hasil yang lebih baik terkait dengan masa depan organisasi (Ross \& Gray, 2006). Para pemimpin transformasional dicirikan oleh empat faktor kunci, yaitu: (1) pengaruh yang bersifat idealis (Karisma), (2) motivasi inspirasional, (3) stimulasi intelektual dan (4) pertimbangan individual. Para pemimpin transformasional berusaha mengintegrasikan antara intuisi dan sensitifitas, opini kreatif dan kekuatan serta ketekunan untuk merancang dan menyusun suatu perpaduan yang harmonis antara strategi dan budaya organisasi. Sebaliknya pemimpin transaksional (transactional leaders) lebih dicirikan oleh "contingent reward" dan "management-byexception style” dari kepemimpinannya. Intinya, pemimpin transaksional mengembangkan sistem pertukaran atau kesepakatan dengan para pengikutnya terkait dengan apa yang akan mereka terima seandainya mereka melakukan sesuatu hal. Mereka umumnya bekerja dibawah aturan yang berlaku, kerangka pengambilan keputusan dan tindakan yang selalu didasarkan pada norma-norma serta prosedur yang menjadikan ciri organisasinya masing-masing (Bass \& Avolio, 1993). Hasil penelitian Porter (2015) berhasil membuktikan adanya pengaruh positif signifikan transformational leadership terhadap organizational commitment.

Givens (2008) dalam penelitiannya menyatakan bahwa pemimpin transformasional mempengaruhi hasil organisasi seperti kinerja in-role dan perilaku ekstra peran (OCB) serta mempengaruhi personal outcome seperti komitmen organisasi dan kepuasan kerja. Organizational citizenship behavior (kinerja extra role) bermanfaat positif bagi organisasi dan anggota organisasi, adanya perilaku positif tanpa pamrih dan turut berpengaruh positif pada kinerja karyawan. Hal ini didukung temuan Gathungu et al. (2015) bahwa kepemimpinan transformational selain mempengaruhi organizational outcome juga mempengaruhi personal outcome seperti komitmen organisasional karyawan. Hasil penelitian Arsawan et al. (2017) menunjukkan bahwa gaya kepemimpinan transformasional berpengaruh positif signifikan terhadap komitmen organisasional karyawan pada UKM di Bali Indonesia. Pada penelitian Farooq et al. (2012) menghasilkan temuan, bahwa hubungan antara kepemimpinan etis supervisor terhadap OCB dimediasi komitmen organisasional afektif.

Kepuasan kerja dan komitmen organisasional juga memberikan dukungan pada perilaku ekstra peran karyawan. Hal ini didukung penelitian Saraswati \& Sulistyo (2017) bahwa kepuasan kerja dan komitmen organisasional berpengaruh positif signifikan terhadap organizational citizenship behavior karyawan PT. Haier Sales Indonesia Bandung Branch. Dalam penelitian Khan (2014); Hatami et al. (2016) diperoleh temuan bahwa kepuasan kerja adalah salah satu faktor yang turut memberikan kontribusi tumbuhnya OCB, karyawan yang merasa puas bekerja akan 
EKONOMI BISNIS DAN KEWIRAUSAHAAN

Vol. VIII, No. 1, Januari 2019

lebih mudah untuk menunjukkan perilaku ekstra perannya di tempat kerja. Temuan lain pada penelitian Huang \& Yu (2011); Bakhshi et al. (2011); Benjamin (2012); Ibrahim \& Aslinda (2013); Subejo et al. (2013); Azizi (2014); Azan (2015); Danish et al. (2015); Sumarwa \& Suryani (2015); Nemati (2016); Obedgiu et al. (2017) menunjukkan bahwa komitmen organisasional memiliki efek positif pada organizational citizenship behavior, semakin tingginya komitmen karyawan terhadap organisasi akan mempengaruhi kinerja karyawan dalam bentuk perilaku ekstra peran.

Dalam beberapa penelitian sebelumnya diperoleh temuan bahwa komitmen organisasional ditemukan sebagai variabel pemediasi pada pengaruh kepemimpinan transformasional dan kepuasan kerja terhadap organizational citizenship behavior. Komitmen organisasional menurut Mowday, Porter \& Steer (1982) merupakan itikad yang kuat seseorang untuk terlibat dalam suatu organisasi, yang terdiri dari (a) keyakinan yang sungguh-sungguh akan tujuan dan nilai-nilai organisasi; (b) kemauan untuk berusaha atau berbuat sesuatu demi kepentingan organisasi; (c) keinginan yang kuat untuk terus menjadi anggota organisasi. Hasil penelitian Khan \& Rashid (2012) dan Almutairi (2016) menunjukkan bahwa komitmen organisasional memediasi pengaruh gaya kepemimpinan transformasional terhadap OCB. Temuan lain ditunjukan dari hasil penelitian Zeinabadi (2010) bahwa komitmen organisasional memediasi pengaruh kepuasan kerja terhadap organizational citizenship behavior. Hasil penelitian Prasetio et al. (2017) menunjukkan bahwa komitmen organisasional memediasi pengaruh kepuasan kerja terhadap OCB karyawan bagian pemasaran pada perbankan di wilayah Bandung. Temuan ini konsisten dengan temuan Dewi \& Suwandana (2016) bahwa komitmen organisasional memediasi pengaruh kepuasan kerja terhadap OCB karyawan Hotel Aget Jaya di Denpasar. Penelitian Barusman \& Mihdar (2014) terhadap pegawai pada kantor Dirjen Pajak di Bengkulu dan Lampung menghasilkan temuan bahwa kepuasan kerja karyawan dapat mempengaruhi organizational citizenship behavior melalui komitmen organisasional.

Bank Perkreditan Rakyat (BPR) mempunyai fungsi yang berbeda dengan bank umum. BPR menghimpun dana dari masyarakat dalam bentuk simpanan berupa deposito berjangka, tabungan, dan pemberian kredit, sedangkan fungsi bank umum menerima simpanan berupa giro, dapat ikut serta dalam lalu lintas pembayaran, kegiatan usaha dalam valuta asing, usaha perasuransian dan usaha lain yang diluar kegiatan usaha yang dapat dilakukan oleh BPR. Keberadaan BPR di Surakarta turut berperan dalam pengembangan Usaha Mikro dan Kecil (UMK). UMK dan masyarakat dapat memanfaatkan pelayanan BPR di PD.BPR Bank Solo, BPR Dana Utama, BPR Bina Langgeng Mulia, BPR Nguter, PT. BPR Suryamas, BPR Central International, BPR Weleri Makmur, PT. BPR UMKM Usaha Madani Karya Mulia, PT. BPR Artha Daya, BPR Rejeki Insani, BPR Suryamas Solo, dan BPR Sukadyarindang.

Untuk memberikan pelayanan yang prima, karyawan BPR di Surakarta harus bekerja sesuai dengan standar-standar yang ditentukan oleh perusahaan. Untuk 
EKONOMI BISNIS DAN KEWIRAUSAHAAN

Vol. VIII, No. 1, Januari 2019

mencapai kinerja yang optimal dituntut perilaku karyawan yang sesuai dengan harapan perusahaan. Dalam kenyataannya, karyawan menunjukkan perilaku yang tidak terdeskripsi secara formal, misalnya suka membantu rekan kerja dalam menyelesaikan tugasnya, kesungguhan dalam mengikuti rapat-rapat perusahaan, namun juga terdapat karyawan yang sering mengeluh terhadap tugas, kurang memperhatikan. Perilaku-perilaku demikian disebut sebagai perilaku ekstra peran (organizational citizenship behavior). Oleh karena itu, perilaku ektra peran (OCB) bagi karyawan BPR di Surakarta amat penting untuk ditumbuhkembangkan karena turut memberikan kontribusi positif terhadap kualitas kehidupan kerja dan kinerja organisasi. Kepemimpinan transformasional, kepuasan kerja, dan komitmen organisasional merupakan anteseden yang dapat memberikan dukungan pada peningkatan organizational citizenship behavior karyawan.

Berdasarkan uraian di atas permasalahan dalam penelitian ini, apakah kepemimpinan transformasional dan kepuasan kerja berpengaruh pada komitmen organisasional, apakah kepemimpinan transformasional, kepuasan kerja komitmen organisasional berpengaruh pada organizational citizenship behavior, apakah komitmen organisasional berperan sebagai pemediasi pada pengaruh kepemimpinan transformasional dan kepuasan kerja terhadap organizational citizenship behavior. Tujuan penelitian ini, untuk menganalisis pengaruh kepemimpinan transformasional dan kepuasan kerja terhadap komitmen organisasional, menganalisis pengaruh kepemimpinan transformasional, kepuasan kerja, dan komitmen organisasional terhadap organizational citizenship behavior, menganalisis peran komitmen organisasional sebagai pemediasi pada pengaruh kepemimpinan transformasional dan kepuasan kerja terhadap organizational citizenship behavior. Hasil dari penelitian ini diharapkan dapat memberikan kontribusi kepada pihak manajemen BPR di wilayah Surakarta, bahwa kepemimpinan transformasional, kepuasan kerja dan komitmen organisasional merupakan faktor yang perlu ditumbuhkembangkan agar memberikan kontribusi positif pada organizational citizenship behavior karyawan.

Berdasarkan permasalahan dan hasil temuan penelitian sebelumnya, peneliti merasa perlu untuk melakukan penelitian tentang "Pengaruh Persepsi Gaya Kepemimpinan Transformasional dan Kepuasan Kerja terhadap Organization Citizenship Behavior: Peran Komitmen Organisasional sebagai Pemediasi (Survey pada Karyawan BPR di Wilayah Surakarta)".

\section{METODE PENELITIAN}

\section{Desain Penelitian}

Jenis penelitian ini adalah penelitian survey dengan menggunakan pendekatan kuantitatif, di mana analisis data yang dilakukan dalam penelitian ini dengan melakukan perhitungan statistik. Desain/rancangan penelitian ini adalah tipe eksplanatori yaitu menjelaskan hubungan kausal antara variabel-variabel melalui pengujian hipotesis. 
EKONOMI BISNIS DAN KEWIRAUSAHAAN

Vol. VIII, No. 1, Januari 2019

\section{Populasi dan Sampel}

Populasi dalam penelitian ini adalah karyawan Bank Perkreditan Rakyat di wilayah Surakarta. Pengambilan sampel menggunakan teknik purposive sampling, karyawan yang digunakan sebagai responden hanya yang memenuhi kriteria yang ditetapkan. yaitu (1) responden bersedia untuk mengisi kuesioner dan bersedia di wawancarai; (2) responden mempunyai pengalaman bekerja di perusahaan minimal 5 tahun. Hal ini dilakukan karena karyawan tersebut telah memiliki waktu untuk mampu mengenal dan beradaptasi dengan lingkungan kerjanya. Berdasarkan hasil penelitian, responden yang memenuhi kriteria sampel adalah 103 karyawan.

\section{Instrumen Penelitian}

Penelitian ini menggunakan empat instrumen meliputi persepsi kepemimpinan transformasional, kepuasan kerja, komitmen organisasional, dan organization citizenship behavior. Persepsi kepemimpinan transformasional adalah sikap karyawan terhadap kepemimpinan atasan yang berorientasi pada perubahan dan visi, serta berupaya memberikan perhatian dan kepuasan kepada pengikut. Persepsi kepemimpinan transformasional diukur dengan menggunakan empat dimensi yang dikembangkan oleh Bass dan Avolio (1993) yaitu individualized influence, inspirational motivation, intellectual stimulation, dan individualized consideration. Kepuasan kerja adalah sikap karyawan terhadap pekerjaan dan berbagai situasi di tempat kerja. Kepuasan kerja diukur dengan lima dimensi yang dikembangkan oleh Luthans (2002) yaitu work, pay, promotion, supervision, and co-worker. Komitmen organisasional adalah komitmen karyawan terhadap organisasi yang menunjukkan adanya suatu kekuatan relatif dari individu dalam menghayati (mengidentifikasi) tujuan dan nilai-nilai organisasi serta tingkat keterlibatannya dalam mendukung tujuan organisasi. Komitmen organisasional diukur dengan tiga dimensi yang dikembangkan Allen \& Meyer (1990) yaitu komitmen afektif, komitmen kontinuan, dan komitmen normatif. Organizational citizenship behavior adalah perilaku karyawan yang bersifat sukarela bukan merupakan tindakan yang terpaksa terhadap hal-hal yang mengedepankan kepentingan organisasi. Organizational citizenship behavior diukur dengan lima dimensi OCB yang dikembangkan Organ (1997) yaitu altruism, conscientiousness, sportmanship, courtesy dan civic virtue.

\section{Teknik Pengumpulan Data}

Teknik pengumpulan data menggunakan kuesioner yang diukur dengan skala Likert 5 poin yaitu Sangat Setuju (5), Setuju (4), Netral (3), Tidak Setuju (2). Sangat Tidak Setuju (1). 


\section{Pengujian Data}

Vol. VIII, No. 1, Januari 2019

Untuk menguji kualitas data dilakukan uji validitas dan reliabilitas instrumen. Pengujian validitas menggunakan rumus Korelasi Product Moment, pengujian reliabilitas menggunakan rumus Cronbach Alpha.

\section{Teknik Analisis Data}

1. Uji Asumsi Klasik

Uji Asumsi Klasik dilakukan melalui empat uji yaitu uji multikolinieritas, uji autokorelasi, uji heteroskedastisitas, dan uji normalitas.

2. Teknik analisis data

Teknik analisis data menggunakan analisis jalur bertujuan untuk mengetahui hubungan kausalitas antara variabel persepsi kepemimpinan transformasional, kepuasan kerja, komitmen organisasional dengan organization citizenship behavior yang dibangun atas dua model persamaan sebagai berikut:

Model 1: $Y_{1}=\alpha+\beta_{1} X_{1}+\beta_{2} X_{2}+\varepsilon_{1}$

Model 2: $Y_{2}=\alpha+\beta_{3} X_{1}+\beta_{4} X_{2}+\beta_{5} Y_{1}+\varepsilon_{2}$

Keterangan:

$\mathrm{X}_{1} \quad=$ Persepsi kepemimpinan transformasional

$\mathrm{X}_{2} \quad=$ Kepuasan kerja

$\mathrm{Y}_{1} \quad=$ Komitmen organisasional

$\mathrm{Y}_{2} \quad=$ Organization citizenship behavior

$\alpha \quad=$ Konstanta

$\beta_{1} \ldots \beta_{5}=$ Koefisien jalur dihitung dari nilai Standardized Coefficient (Beta)

$\varepsilon=$ Jumlah variance yang tak dapat dijelaskan (Unexplained variance)

3. Pengujian Hipotesis

Pengujian pengaruh langsung (hipotesis $1 \mathrm{~s} / \mathrm{d}$ hipotesis 5) dilakukan melalui uji t dengan menggunakan tingkat signifikansi 5\%. Pengujian pengaruh mediasi (hipotesis 6 dan 7) dengan membandingkan total koefisien pengaruh tidak langsung > koefisien pengaruh langsung.

\section{HASIL PENELITIAN}

\section{Karakteristik Demografi}

Karakteristik demografi responden disajikan seperti tabel berikut.

Tabel 1: Analisis Karakteristik Demografi Responden

\begin{tabular}{|c|c|c|c|}
\hline Karakteristik & Keterangan & Jumlah (orang) & Persentase $(\%)$ \\
\hline \multirow[t]{3}{*}{ Jenis Kelamin } & Laki-laki & 41 & 39,81 \\
\hline & Perempuan & 62 & 60,19 \\
\hline & Total & 103 & 100,00 \\
\hline Tingkat & SMA & 25 & 24,27 \\
\hline \multirow[t]{2}{*}{ Pendidikan } & Diploma (D1/D2/D3) & 26 & 25,24 \\
\hline & Sarjana $(\mathrm{S} 1)$ & 43 & 41,75 \\
\hline
\end{tabular}


EKONOMI BISNIS DAN KEWIRAUSAHAAN

Vol. VIII, No. 1, Januari 2019

\begin{tabular}{llcr}
\hline & Sarjana $(\mathrm{S} 2)$ & 9 & 8,74 \\
\hline & Total & 103 & 100,00 \\
\hline \multirow{3}{*}{ Masa Kerja } & $5-10$ tahun & 32 & 31,07 \\
& $10-15$ tahun & 57 & 55,34 \\
& $>15$ tahun & 14 & 13,59 \\
\hline & Total & 103 & 100 \\
\hline
\end{tabular}

\section{Hasil Uji Validitas dan Reliabilitas Instrumen}

Berdasarkan pengolahan data dengan program SPSS berikut ini disajikan hasil uji validitas butir pernyataan variabel persepsi kepemimpinan transformasional, kepuasan kerja, komitmen organisasional, dan organization citizenship behavior.

Tabel 2: Hasil Uji Validitas

\begin{tabular}{llccc}
\hline Variabel & Item & r hitung & r table & Kesimpulan \\
\hline Persepsi & KEPTRANS1 & 0,550 & 0,195 & Valid \\
Kepemimpinan & KEPTRANS2 & 0,426 & 0,195 & Valid \\
Transformasional & KEPTRANS3 & 0,504 & 0,195 & Valid \\
& KEPTRANS4 & 0,451 & 0,195 & Valid \\
& KEPTRANS5 & 0,458 & 0,195 & Valid \\
Kepuasan Kerja & KEPTRANS6 & 0,423 & 0,195 & Valid \\
& KEP1 & 0,537 & 0,195 & Valid \\
& KEP2 & 0,494 & 0,195 & Valid \\
& KEP3 & 0,520 & 0,195 & Valid \\
Komitmen & KEP4 & 0,454 & 0,195 & Valid \\
Oragnisasional & KEP5 & 0,477 & 0,195 & Valid \\
& KOMIT1 & 0,517 & 0,195 & Valid \\
& KOMIT2 & 0,514 & 0,195 & Valid \\
& KOMIT3 & 0,570 & 0,195 & Valid \\
OCB & KOMIT4 & 0,561 & 0,195 & Valid \\
& KOMIT5 & 0,568 & 0,195 & Valid \\
& OCB1 & 0,756 & 0,195 & Valid \\
& OCB2 & 0,780 & 0,195 & Valid \\
& OCB3 & 0,730 & 0,195 & Valid \\
& OCB4 & 0,777 & 0,195 & Valid \\
& OCB5 & 0,798 & 0,195 & Valid \\
& OCB6 & 0,768 & 0,195 & Valid \\
& OCB7 & 0,746 & 0,195 & Valid \\
& OCB8 & 0,778 & 0,195 & Valid \\
& OCB9 & 0,772 & 0,195 & Valid \\
\hline
\end{tabular}

Sumber : Data primer diolah, 2018

Perhitungan validitas item dengan uji korelasi product moment menunjukkan bahwa semua butir pernyataan untuk variabel persepsi kepemimpinan transformasional, kepuasan kerja, komitmen organisasional, dan organization citizenship behavior menghasilkan nilai $r$ hitung $>\mathrm{r}$ tabel berarti semua item pernyataan variabel persepsi 
EKONOMI BISNIS DAN KEWIRAUSAHAAN

Vol. VIII, No. 1, Januari 2019

kepemimpinan transformasional, kepuasan kerja, komitmen organisasional, dan organization citizenship behavior Valid.

Berdasarkan pengolahan data dengan program SPSS berikut ini disajikan hasil uji reliabilitas untuk instrumen persepsi kepemimpinan transformasional, kepuasan kerja, komitmen organisasional, dan organization citizenship behavior.

Tabel 3: Hasil Uji Reliabilitas Instrumen

\begin{tabular}{lccc}
\hline \multicolumn{1}{c}{ Variabel } & Cronbach Alpha & Kriteria uji & Kesimpulan \\
\hline Persepsi kepemimpinan & & & \\
transformasional & 0,926 & 0,60 & Reliabel \\
$\begin{array}{l}\text { Kepuasan kerja } \\
\text { Komitmen organisasional }\end{array}$ & 0,942 & 0,60 & Reliabel \\
$\begin{array}{l}\text { Organization citizenship } \\
\text { behavior }\end{array}$ & 0,941 & 0,60 & Reliabel \\
\hline Sehber: Data primer & 0,964 & 0,60 & Reliabel \\
\hline
\end{tabular}

Sumber: Data primer diolah, 2018

Berdasarkan hasil uji reliabilitas diketahui bahwa instrumen persepsi kepemimpinan transformasional, kepuasan kerja, komitmen organisasional, dan organization citizenship behavior menghasilkan cronbach alpha $>0,6$ berarti seluruh instrumen penelitian ini reliabel.

\section{Hasil Uji Asumsi Klasik}

Berdasarkan pengolahan data dengan program SPSS berikut ini disajikan hasil uji asumsi klasik meliputi Uji multikolinieritas, uji heteroskedastisitas, uji autokorelasi, dan uji normalitas.

\section{Uji Multikolinieritas}

Hasil uji multikolinieritas disajikan seperti tabel 4 berikut ini.

Tabel 4: Hasil Uji Multikolinieritas

\begin{tabular}{lccccl}
\hline \multicolumn{1}{c}{ Variabel } & Tolerance & VIF & \multicolumn{1}{c}{ Standar } & \multicolumn{1}{c}{ Keterangan } \\
\hline $\begin{array}{l}\text { Persepsi kepemimpinan } \\
\text { transformasional }\end{array}$ & 0,940 & 1,064 & & & $\begin{array}{l}\text { Tidak terjadi } \\
\text { ultikolinieritas }\end{array}$ \\
$\begin{array}{l}\text { Kepuasan kerja } \\
\text { Komitmen }\end{array}$ & 0,934 & 1,071 & $\begin{array}{c}\text { Tolerance } \\
>0,1\end{array}$ & $\begin{array}{c}\text { VIF }< \\
10\end{array}$ & $\begin{array}{l}\text { Tidak terjadi } \\
\text { multikolinieritas }\end{array}$ \\
organisasional & 0,882 & 1,134 & & & $\begin{array}{l}\text { Tidak terjadi } \\
\text { multikolinieritas }\end{array}$ \\
\hline
\end{tabular}

Sumber : Data primer yang diolah, 2018

Hasil uji multikolinieritas menunjukkan bahwa semua variabel independen (kepemimpinan transformasional, kepuasan kerja, komitmen organisasional) tidak saling berkorelasi linier. Hal ini ditunjukkan dari nilai tolerance $(0,940 ; 0,934$; $0,882)>0,1$ dan Variance Inflation Factors $(1,064 ; 1,071 ; 1,134)<10$. Dengan demikian model penelitian ini tidak terjadi multikolinieritas.

\section{Uji Heteroskedastisitas}

Hasil uji heteroskedastisitas disajikan seperti tabel berikut ini. 
EKONOMI BISNIS DAN KEWIRAUSAHAAN

Vol. VIII, No. 1, Januari 2019

Tabel 5: Hasil Uji Heteroskedastistas

\begin{tabular}{|c|c|c|c|}
\hline Variabel & Sig. & Standar & Keterangan \\
\hline $\begin{array}{l}\text { Persepsi kepemimpinan } \\
\text { transformasional }\end{array}$ & 0,540 & & Tidak terjadi heteroskedastisitas \\
\hline Kepuasan kerja & 0,881 & Sig. $>0,05$ & Tidak terjadi heteroskedastisitas \\
\hline $\begin{array}{l}\text { Komitmen } \\
\text { organisasional }\end{array}$ & 0,670 & & Tidak terjadi heteroskedastisitas \\
\hline
\end{tabular}

Sumber : Data primer yang diolah, 2018

Hasil uji heteroskedastisitas menunjukkan bahwa semua variabel independen (kepemimpinan transformasional, kepuasan kerja, komitmen organisasional) tidak berpengaruh signifikan terhadap variabel absolut residual. Hal ini ditunjukkan dengan nilai signifikansi $(0,540 ; 0,881 ; 0,670)>0,05$, berarti model penelitian ini tidak terjadi masalah heteroskedastisitas.

\section{Uji Autokorelasi}

Hasil uji autokorelasi disajikan seperti tabel berikut ini.

Tabel 6: Hasil Uji Autokorelasi

\begin{tabular}{ccc}
\hline $\begin{array}{c}\text { Asymp. } \text { Sig. } \\
(2 \text {-tailed })\end{array}$ & Standar & Keterangan \\
\hline 0,412 & Sig. $>0,05$ & Tidak terjadi autokorelasi \\
\hline
\end{tabular}

Sumber : Data primer yang diolah, 2018

Hasil uji autokorelasi melalui Runs test diperoleh Asymp.Sig.(2-tailed) sebesar 0,412 $>0,05$. Dengan demikian model penelitian ini tidak terjadi masalah autokorelasi.

\section{Uji Normalitas}

Hasil uji normalitas disajikan seperti tabel berikut ini.

Tabel 7: Hasil Uji Normalitas

\begin{tabular}{ccc}
\hline Asymp. Sig.(2-tailed) & Standar & Keterangan \\
\hline 0,183 & Sig. $>0,05$ & Residual Normal \\
\hline
\end{tabular}

Sumber : Data primer yang diolah, 2018

Hasil uji normalitas melalui Kolmogorov-Smirnov test diperoleh Asymp.Sig.(2-tailed) sebesar 0,183>0,05 berarti residual normal.

\section{Hasil Analisis Jalur}

Langkah-langkah perhitungan analisis jalur dilakukan dengan melakukan analisis regresi terhadap ketiga model, dengan menggunakan bantuan program SPSS. Berdasarkan analisis regresi yang dilakukan, diperoleh hasil sebagai berikut.

Tabel 8: Hasil Analisis Jalur

\begin{tabular}{clcccc}
\hline $\begin{array}{c}\text { Model } \\
\text { Regresi }\end{array}$ & \multicolumn{1}{c}{ Jalur } & $\begin{array}{c}\text { Koefisien } \\
\text { jalur }\end{array}$ & Nilai t & Sig. & Kesimpulan \\
\hline 1 & KEPTRANS $\rightarrow$ KOMIT & $\beta 1=0,229$ & 2,427 & 0,017 & H1 diterima \\
& KEP $\rightarrow$ KOMIT & $\beta 2=0,241$ & 2,563 & 0,012 & H2 diterima \\
\hline 2 & KEPTRANS $\rightarrow$ OCB & $\beta 3=0,251$ & 3,036 & 0,003 & H3 diterima \\
& KEP $\rightarrow$ OCB & $\beta 4=0,324$ & 3,912 & 0,000 & H4 diterima \\
\hline
\end{tabular}


EKONOMI BISNIS DAN KEWIRAUSAHAAN

Vol. VIII, No. 1, Januari 2019

$\mathrm{KOMIT} \rightarrow \mathrm{OCB}$

$\beta 5=0,311$

3,654
$0,000 \quad$ H5 diterima

Tabel 9: Hasil Perhitungan Pengaruh Langsung (Direct Effect) dan Pengaruh Tidak Langsung (Indirect Effect)

\begin{tabular}{lccccc}
\hline \multicolumn{1}{c}{ Jalur } & $\begin{array}{c}\text { Koefisien } \\
\text { Jalur }\end{array}$ & $\begin{array}{c}\text { Direct } \\
\text { Effect }\end{array}$ & $\begin{array}{c}\text { Indirect } \\
\text { Effect }\end{array}$ & $\begin{array}{c}\text { Total } \\
\text { Indirect } \\
\text { Effect }\end{array}$ & Kesimpulan \\
\hline KEPTRANS $\rightarrow$ KOMIT & $\beta 1=0,229$ & & & & \\
KEP $\rightarrow$ KOMIT & $\beta 2=0,241$ & & & & \\
KEPTRANS $\rightarrow$ OCB & $\beta 3=0,251$ & & & & \\
KEP $\rightarrow$ OCB & $\beta 4=0,324$ & & & & \\
KOMIT $\rightarrow$ OCB & $\beta 5=0,311$ & & & & \\
\hline KEPTRANS $\rightarrow$ KOMIT $\rightarrow$ OCB & & $\beta 3=0,251$ & $\beta 1 \times \beta 5=0,071$ & 0,322 & H6 diterima \\
\hline KEP $\rightarrow$ KOMIT $\rightarrow$ OCB & & $\beta 4=0,324$ & $\beta 2 \times \beta 5=0,075$ & 0,399 & H7 diterima \\
\hline
\end{tabular}

\section{Pengujian Hipotesis}

1. Persepsi kepemimpinan transformasional berpengaruh signifikan terhadap komitmen organisasional, dengan $p$ value sebesar 0,017. Dengan demikian hipotesis 1 diterima.

2. Kepuasan kerja berpengaruh signifikan terhadap komitmen organisasional, dengan $p$ value sebesar 0,012. Dengan demikian hipotesis 2 diterima.

3. Persepsi kepemimpinan transformasional berpengaruh signifikan terhadap organization citizenship behavior, dengan $p$ value sebesar 0,003. Dengan demikian hipotesis 3 diterima.

4. Kepuasan kerja berpengaruh signifikan terhadap organization citizenship behavior, dengan $p$ value sebesar 0,000. Dengan demikian hipotesis 4 diterima.

5. Komitmen organisasional berpengaruh signifikan terhadap organization citizenship behavior, dengan $p$ value sebesar 0,000. Dengan demikian hipotesis 5 diterima.

6. Komitmen organisasional memediasi pengaruh persepsi kepemimpinan transformasional terhadap organization citizenship behavior ditunjukkan dari total koeefisien pengaruh tidak langsung $(0,322)>$ koefisien pengaruh langsung $(0,251)$. Dengan demikian hipotesis 6 diterima.

7. Komitmen organisasional memediasi pengaruh kepuasan kerjaterhadap organization citizenship behavior ditunjukkan dari total koeefisien pengaruh tidak langsung $(0,399)>$ koefisien pengaruh langsung $(0,324)$. Dengan demikian hipotesis 7 diterima.

\section{Uji F}

Hasil pengujian model diperoleh nilai $\mathrm{F}$ hitung sebesar 19,068 dengan $p$ value $(0,000)<0,05$ berarti model dinyatakan layak (fit) dalam memprediksi pengaruh persepsi kepemimpinan transformasional, kepuasan kerja, dan komitmen organisasional terhadap organization citizenship behavior. 
EKONOMI BISNIS DAN KEWIRAUSAHAAN

Vol. VIII, No. 1, Januari 2019

\section{Uji Koefisien Determinasi}

Uji koefisien determinasi Adjusted $R^{2}$ bertujuan untuk mengukur besarnya persentase sumbangan pengaruh persepsi kepemimpinan transformasional, kepuasan kerja, dan komitmen organisasional terhadap organization citizenship behavior. Berdasarkan hasil analisis regresi diperoleh nilai koefisien determinasi Adjusted $R^{2}$ sebesar 0,347 artinya sumbangan pengaruh persepsi kepemimpinan transformasional, kepuasan kerja, dan komitmen organisasional terhadap organization citizenship behavior adalah sebesar $34,7 \%$ sisanya $65,3 \%$ dijelaskan oleh variabel lain.

Berdasarkan hasil analisis jalur disajikan rangkuman koefisien direct effect dan indirect effet seperti pada skema berikut.

H6

Total PTL $>$ PL

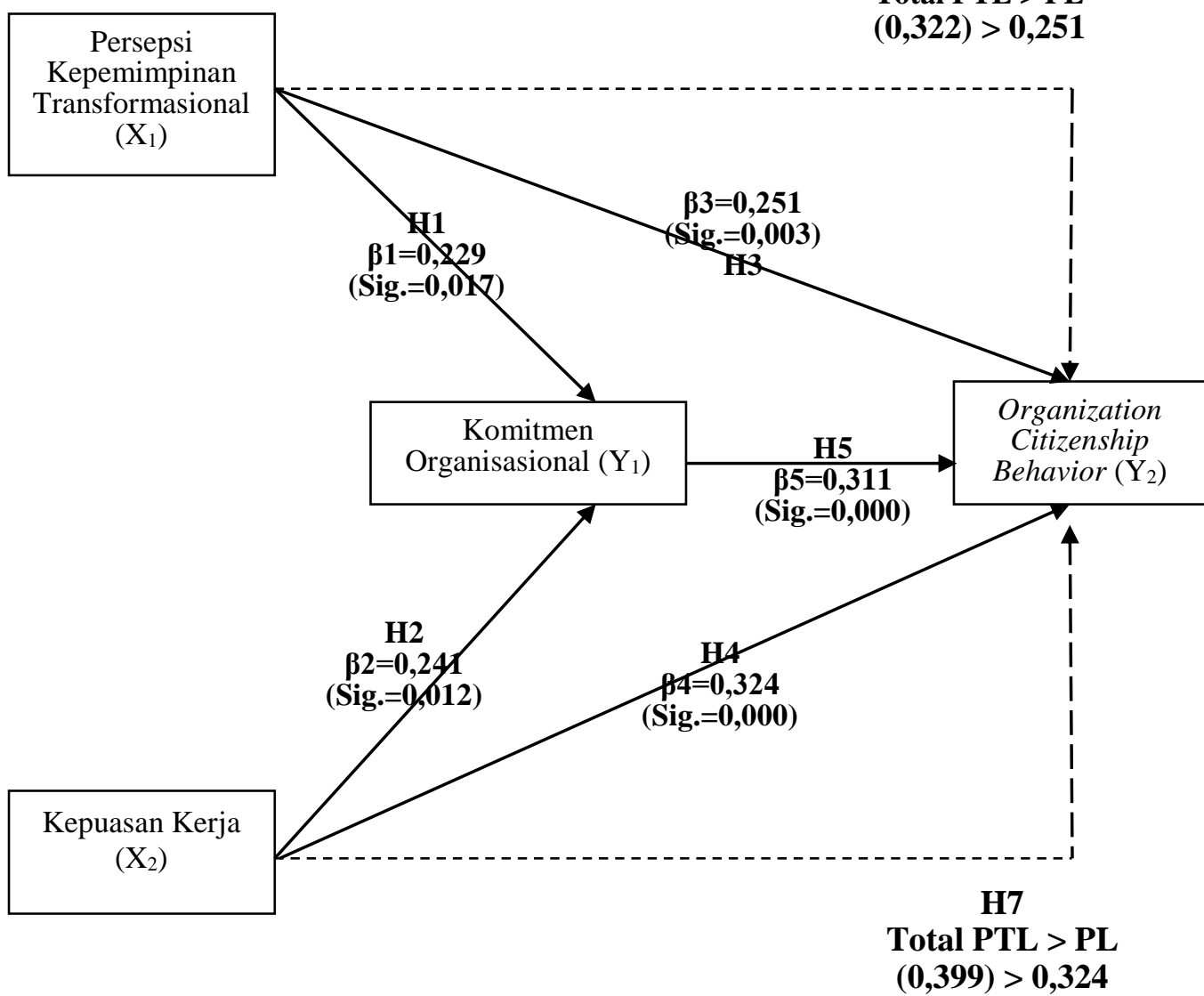

\section{PEMBAHASAN}

1. Pengaruh persepsi kepemimpinan transformasional dan kepuasan kerja terhadap komitmen organisasional

Hasil penelitian ini berhasil membuktikan bahwa persepsi kepemimpinan transformasional dan kepuasan kerja berpengaruh signifikan terhadap komitmen organisasional karyawan BPR di wilayah Surakarta. Hasil temuan ini, memberikan pemahaman pentingnya pengembangan kepemimpinan trasformasional dalam membangun komitmen organisasional karyawan 
Vol. VIII, No. 1, Januari 2019

khususnya di lingkungan organisasi BPR di Surakarta. Dari sudut pandang teoritis, tinjauan literatur yang dikemukakan Givens (2008) memperkuat model konseptual kepemimpinan transformasional yang diusulkan oleh Bass (1985) bahwa kepemimpinan transformasional secara signifikan berkorelasi dengan personal outcome (hasil individu/pengikut) yang artinya bahwa kepemimpinan transformasional memiliki pengaruh positif pada komitmen karyawan terhadap organisasi. Untuk membangun komitmen organisasional karyawan, pemimpin transformasional perlu mengembangkan empat karakteristik yaitu pengaruh yang bersifat idealis (karisma), motivasi inspirasional, stimulasi intelektual dan pertimbangan individual.

Menurut Rehman et al. (2013: 80) kepuasan kerja dan komitmen organisasional memiliki hubungan yang positif, karyawan yang komit terhadap pekerjaan dan tujuan organisasi ditunjukkan dari kepuasan karyawan dalam bekerja. Hasil temuan penelitian ini mendukung penelitian yang dilakukan oleh Malik et al., (2010); Nagar (2012); Rehman et al. (2013); Yamsul et al., (2013 bahwa kepuasan kerja memiliki pengaruh positif terhadap komitmen organisasional. Komitmen karyawan terhadap organisasi terbentuk karena adanya perasan puas karyawan terhadap pekerjaan. Implikasi dari temuan ini, komitmen organisasional karyawan BPR di Surakarta merupakan konsekuensi dari adanya kepuasan kerja. Karyawan yang memperoleh kepuasan dalam bekerja akan berkomitmen untuk memajukan organisasinya, dengan menunjukkan kesetiaan, keterlibatan, dan rasa memiliki organisasi yang semakin tinggi.

2. Pengaruh persepsi kepemimpinan transformasional, kepuasan kerja, dan komitmen organisasional terhadap organization citizenship behavior

Hasil penelitian ini berhasil membuktikan bahwa persepsi kepemimpinan transformasional, kepuasan kerja dan komitmen organisasional berpengaruh signifikan terhadap organization citizenship behavior karyawan BPR di wilayah Surakarta. Temuan ini medukung penelitian Bass \& Avolio (1995); dan Givens (2008) bahwa kepemimpinan transformasional berdampak pada outcomes organisasi (organizational outcomes). Pemimpin transformasional mempengaruhi bawahan dengan memotivasi dan menginspirasi mereka untuk mencapai tujuan organisasi. Pemimpin transformasional juga mencoba untuk membantu para bawahan untuk mencapai hasil yang lebih baik terkait dengan masa depan organisasi, sehingga pemimpin transformasional turut mempengaruhi hasil organisasi seperti organization citizenship behavior. Kepemimpinan transformasional dapat menciptakan perilaku ekstra peran karyawan. OCB karyawan ditunjukkan dari perilaku mereka untuk menghasilkan pekerjaan terbaik melebihi apa yang diharapkan bagi organisasinya seperti kebajikan, membantu, sportif, kesopanan, dan altruisme (Bass, 1990 dan Givens, 2008).

Kepuasan kerja dan komitmen organisasional karyawan memiliki link positif dengan organization citizenship behavior. Karyawan yang puas dalam pekerjaannya dan menunjukkan komitmen pada organisasi akan memberikan 
EKONOMI BISNIS DAN KEWIRAUSAHAAN

Vol. VIII, No. 1, Januari 2019

kontribusi bagi organisasi. Kontribusi yang diberikan karyawan pada organisasi dapat diwujudkan dalam bentuk in-role performance (kinerja) dan exstra-role performance (organizational citizenship behavior/perilaku ekstra peran. Hal ini didukung dari temuan penelitian Organ (1988); LePine et al. (2002); Givens (2008).

3. Pengaruh persepsi kepemimpinan transformasional dan kepuasan kerja terhadap organization citizenship behavior melalui komitmen organisasional

Hasil temuan penelitian ini berhasil membuktikan bahwa persepsi kepemimpinan transformasional dan kepuasan kerja mempengaruhi organization citizenship behavior melalui komitmen organisasional karyawan BPR di wilayah Surakarta. Temuan ini mendukung hasil penelitian sebelumnya yang dilakukan oleh Khan \& Rashid (2012) dan Almutairi (2016) bahwa komitmen organisasional memediasi pengaruh gaya kepemimpinan transformasional terhadap organization citizenship behavior karyawan. Temuan ini juga sejalan dengan penelitian yang dilakukan oleh Zeinabadi (2010) bahwa komitmen organisasional memediasi pengaruh kepuasan kerja terhadap organizational citizenship behavior. Hasil penelitian Prasetio et al. (2017) menunjukkan bahwa komitmen organisasional memediasi pengaruh kepuasan kerja terhadap OCB karyawan bagian pemasaran pada perbankan di wilayah Bandung. Temuan ini juga sejalan dengan temuan Dewi \& Suwandana (2016) bahwa komitmen organisasional memediasi pengaruh kepuasan kerja terhadap OCB karyawan Hotel Aget Jaya di Denpasar. Temuan ini konsisten dengan penelitian Barusman \& Mihdar (2014) bahwa komitmen organisasional memediasi pengaruh kepuasan kerja terhadap OCB karyawan Kantor Dirjen Pajak di Bengkulu dan Lampung. Implikasi dari hasil temuan ini, perilaku ekstra peran karyawan BPR di wilayah Surakarta dapat semakin tumbuh apabila sebelumnya komitmen organisasional karyawan semakin mendapat dukungan dari perusahaan. Untuk membangun komitmen organisasional karyawan, perusahaan perlu mengembangkan kepemimpinan transformasional dan mewujudkan kepuasan kerja bagi karyawan.

\section{KESIMPULAN, KETERBATASAN, DAN SARAN Kesimpulan}

Berdasarkan hasil pengujian setiap hipotesis diperoleh kesimpulan bahwa persepsi kepemimpinan transformasional dan kepuasan kerja dapat mempengaruhi langsung komitmen organisasional. Persepsi kepemimpinan transformasional, kepuasan kerja, dan komitmen organisasional dapat mempengaruhi langsung organizational citizenship behavior. Penelitian ini juga berhasil membuktikan peran komitmen organisasional sebagai pemediasi pada pengaruh persepsi kepemimpinan transformasional dan kepuasan kerja terhadap organizational citizenship behavior. Temuan ini memberikan implikasi stratejik bagi pimpinan BPR di Surakarta, bahwa 
EKONOMI BISNIS DAN KEWIRAUSAHAAN

Vol. VIII, No. 1, Januari 2019

organizational citizenship behavior karyawan dapat ditumbuhkembangkan melalui komitmen organisasional, dan untuk membangun komitmen organisasional karyawan perlu didukung dengan kepemimpinan transformasional yang efektif dan peningkatan kepuasan kerja karyawan.

\section{Keterbatasan Penelitian}

Penelitian ini terbatas pada sampel karyawan BPR di wilayah Surakarta, sehingga hasilnya tidak bisa digeneralisasikan pada perusahaan yang lain. Pendekatan kontijensi dalam penelitian ini hanya menggunakan satu variabel pemediasi. Untuk lebih menyempurnakan hasil penelitian ini, masih diperlukan penelitian lebih lanjut dengan mempertimbangkan variabel-variabel lain yang mempengaruhi organizational citizenship behavior, seperti kompensasi, budaya organisasi, dan lain-lain.

\section{Saran}

Upaya perusahaan menumbuhkembangkan organizational citizenship behavior karyawan amat penting dilakukan karena turut memberikan kontribusi positif terhadap kualitas kehidupan kerja dan kinerja organisasi BPR di Surakarta. Untuk mencapai tujuan tersebut, perusahaan perlu mengembangkan kepemimpinan transformasional, memantau kepuasan kerja dan memelihara komitmen organisasional karyawan. Penelitian yang akan datang disarankan untuk menambahkan variabel-variabel lain yang mempengaruhi in-role atau extra-role performance. 
EKONOMI BISNIS DAN KEWIRAUSAHAAN

Vol. VIII, No. 1, Januari 2019

\section{DAFTAR PUSTAKA}

Allen, N.J and Meyer, J.P., 1990, "The Measurement and Antecedents of Affective, Continuance and Normative Commitment to the Organization", Journal of Occupational Psychology, Vol. 63, pp. 1-18.

Almutairi, D.O., 2016, "The Mediating Effects of Organizational Commitment on the Relationship between Transformational Leadership Style and Job Performance", International Journal of Business and Management, Vol. 11 (1), pp.231-241.

Arsawan, W.E., Pasek, K., and Suryantini, S.P.S., 2017, "Impact of Transformational and Transactional Leadership Style on Organizational Commitment and SMEs Business Performance: A Comparatif Analysis", International Business Management, Vol. 11 (8-10), pp. 1583-1591.

Azan, P.G., 2015, "Pengaruh Organizational Commitment dan Professional Commitment terhadap Organizational Citizenship Behavior Karyawan PT. Telkomsel Pekanbaru", Jom FEKOM, Vol. 2 (2), Hal. 1-11.

Azizi, B., Alipour, B., Mehni, M.A.K., and Shojaee, K., 2014, "Relationship between organizational commitment and organizational citizenship behavior in sport teachers in department of education from Sanandaj", Advances in Applied Science Research, Vol. 5 (4), pp. 95-99.

Bakhshi, A., Sharma, A.D., and Kumar, K., 2011, "Organizational Commitment as predictor of Organizational Citizenship Behavior", European Journal of Business and Management, Vol 3 (4), pp. 78-87.

Bass, B.M., Avolio, B.K., Jung D.I., dan Berson, Y. (2003). Predicting Unit Performance by Assessing Transformational and Transactional Leadership, Journal of Applied Psychology: The American Psychological Association Inc., Vol. 88 (2), 207-218.

Bass, BM., \& Avolio, Bruce J., 1993, Transformational Leadership and Organizational Culture, Journal of PAQ Spring. Suny-Binghamton, pp. 112121.

Barusman, A.R.P. and Mihdar, F., 2014, "The Effect of Job Satisfaction and Organizational Justice on Organizational Citizenship Behavior with Organization Commitment as the Moderator", International Journal of Humanities and Social Science, Vol. 4(9), pp. 118-126.

Benjamin, A., 2012, "The Influence of Affective Commitment on Citizenship Behavior and Intention to Quit among Commercial Banks' Employees in Nigeria", Journal of Management and Sustainability, Vol. 2 (2), pp. 54-68.

Burns, J. M., 1978, Leadership. New York: Harper \& Row.

Danish, R.O., Humayon, A.A., Shahid, A.U., Nawaz, M.M., 2015, “Association of Affective Commitment with Organizational Citizenship Behaviour and Task Performance of Employees in Banking Sector", e-Journal of Yasar University, Vol. 10, Special Issue, pp. 56-67. 
Dewi, Ni Luh Putu Yanti Astika dan Suwandana, I Gusti Made, 2016, "Pengaruh Kepuasan Kerja terhadap Organizational Citizenship Behavior (OCB) dengan Komitmen Organisasional Sebagai Variabel Mediasi”, e-Jurnal Manajemen Unud, Vol. 5 (9), Hal. 5643-5670.

Dobre, Ovidiu-Iliuta, 2013, "Employee motivation and organizational performance", Review of Applied Socio-Economic Research, Vol. 5 (1), pp. 53-60.

Farooq A., Islam, T., Khan, S.R., and Ungku, U.N., 2012, "Investigating the Mediating Role of Affective Commitment Between Supervisor's Ethical Leadership and Citizenship Behaviors", World Applied Sciences Journal, Vol. 19 (8), pp. 1221-1224.

Gathungu, E.W.M., Iravo, M.A., and Namusonge, G.S., 2015, "Transformational Leadership and Employee's Commitment: Empirical Review", Journal of Humanities and Social Science (IOSR-JHSS), Vol. 20 (7), pp. 1-07.

Hatami, K., Esmaeili, M.R., and Sajadi, S.H., 2016, "Predict organizational citizenship behavior of the staff based on the factors of the job satisfaction", Turkish Journal of Sport and Exercise, Vol. 18(2), pp. 97-102.

Huang, C.C., and You, C.S., 2011, "The three components of organizational commitment on in-role behaviors and organizational citizenship behaviors", African Journal of Business Management, Vol. 5(28), pp.11335-11344.

Ibrahim, M.A. and Aslinda, 2013, "Relationship between Organizational Commitment and Organizational Citizenship Behavior (OCB) At GovernmentOwned Corporation Companies", Journal of Public Administration and Governance, Vol. 3 (3), pp. 35-42.

Khan, R., 2014, "Impact of OCB-Specific Meanings on Employees' Display of OCB: A Perspective in Pakistan", International Journal Management Business, Vol. 4 (4), pp. 319-333.

Khan, S.K., and Rashid, M.Z.A., 2015, "The Mediating Effect of Organization Commitment in the Organization Culture, Leadership and Organization Justice Relationship with Organization Citizenship Behaviour: A study of Academics in Private Higher Learning Institutions in Malaysia", International Journal of Recent Advances in Organizational Behaviour and Decision Sciences (IJRAOB), Vol. 1 (2), pp. 335-359.

LePine, Jeffrey A., Erez, Amir dan Johnson, Diane E., 2002, "The Nature and Dimensionality of Organizational Citizenship Behavior: A Critical Review and Meta-Analysis", Journal of Applied Psychology, the American Psychological Association, Inc., Vol. 87 (1), p.52-65.

Luthans, F., 2002, Organizational Behavior, Seventh Edition, McGraw-Hill Inc.

Mooday, R.T., Porter, L.W., \& Steer, R.M., 1982. Employees organization linkages, Academic Press, New York. 
EKONOMI BISNIS DAN KEWIRAUSAHAAN

Vol. VIII, No. 1, Januari 2019

Nemati, M.A., Safooei, M.A., Zangiyan, S., and Ranani, M.B., 2016, "The Role of Social Capital, Commitment, and Organizational Citizenship Behavior in Improving Job Performance (Case Study: Khoy Municipality)", A Quarterly Journal of Urban Economics and Management, Vol. 5,No. 1(17), pp. 111-122.

Obedgiu, V., Bagire, V., and Mafabi, S., 2017, "Examination of organizational commitment and organizational citizenship behaviour among local government civil servants in Uganda", Journal of Management Development, Vol. 36 (1), pp. 1304-1316.

Organ, D.W., 1988, Organizational citizenship behavior: The good soldier syndrome. Lexington, MA: Lexington Books.

Organ, D.W., 1997, “Organization Citizenship Behaviour: its construct Clean-Up Time", Human Performance, Vol. 10 (2), pp. 85-97.

Porter, J.A., 2015, "The relationship between transformational leadership and organizational commitment in nonprofit long term care organizations: The direct care worker perspective", Creighton Journal of Interdisciplinary Leadership, Vol. 1 (2), pp. 68-85.

Prasetio, A.P., Yuniarsih, T., Ahman, E., 2017, "Job Satisfaction, Organizational Commitment, and Organizational Citizenship Behaviour in State-owned Banking", Universal Journal of Management, Vol. 5(1), pp. 32-38.

Ross, J.A., \& Gray, P., 2006, "School Leadership and Student Achievement: The Mediating Effects of Teacher Beliefs", Canadian Journal of Education, Vol. 29 (33), pp. 798-822.

Steers, R.M., L.W. Porter. \& G.A. Bigley. 1996. Motivation and leadership at work. New York: McGraw-Hill.

Saraswati, V.A. dan Sulistyo, S.D., 2017, "The Influence of Job Satisfaction and Orgaizational Commitment on The Organizational Citizenship Behavior in PT. Haier Sales Indonesia Bandung Branch”, Journal of Engineering and Applied Sciences, Vol. 12 (2), pp. 439-446.

Subejo, Troena, E.A., Thoyib, A., and Aisjah, S., 2013, "The Effect of Organizational Commitment and Organization Identity Strength to Citizenship Behaviour (OCB) Impact on Fire Department and Disaster Employee Performance in Jakarta Indonesia", IOSR Journal of Business and Management (IOSR-JBM), Vol. 10 (3), pp. 30-36.

Sumarwa, I.W.G. and Suryani, N.K., 2015, "Commitment and Competency as An Organizational Citizenship Behaviour Predictor and Its Effect On The Performance A Study of Private Vocational High Schools in Klungkung Regency, Bali, Indonesia", International Journal of Economics, Commerce and Management, Vol. 3 (1), pp. 1-13.

Zeinabadi, Hassanreza, 2010, "Job satisfaction and organizational commitment as antecedents of Organizational Citizenship Behavior (OCB) of teachers", Procedia Social and Behavioral Sciences, Vol. 5, pp. 998-1003. 